\title{
THE PRESENCE OF GEOPHYSICAL LOADINGS IN GPS OBSERVATIONS USING GENERAL LEAST SQUARES APPROACHES
}

\author{
N. S. A. Alihan ${ }^{1 *}$, D. D. Wijaya ${ }^{3}$, A. H. M. Din ${ }^{1,2^{*}}$ and A. H. Omar ${ }^{1}$ \\ ${ }^{1}$ Geomatic Innovation Research Group (GnG), ${ }^{2}$ Geoscience and Digital Earth Centre (INSTEG), Faculty of Built Environment and \\ Surveying, Universiti Teknologi Malaysia, 81310 Johor Bahru, Johor, Malaysia. \\ ${ }^{3}$ Geodesy Research Group, Faculty of Earth Sciences and Technology, Institute of Technology Bandung, Bandung, Indonesia. \\ nsatikah99@gmail.com; amihassan@utm.my
}

KEY WORDS: Geophysical Loadings, Earth Body Tide, Ocean Tide Loading, GPS Observation

\begin{abstract}
:
The earth's crust undergoes natural deformation due to the geophysical loadings that consist of the earth body tide, ocean tide loading, atmospheric pressure loading and pole tide. This periodic displacement is generated by the changes of the gravitational attraction between the moon and the sun acting upon the earth's rotation, along with the temporal atmospheric changes and the variability of the ocean tide. The study of the geophysical loadings is important in the geodesy field as the magnitude of the signals is significant and can contribute to errors in space geodetic measurements such as Global Positioning System (GPS), Very-Long Baseline Interferometry (VLBI) and Altimeter. This study is conducted to evaluate the percentage of geophysical loadings in GPS observations by adopting general least square approaches. The presence of the geophysical loadings indicates that as many as $76 \%$ to 93\% of the geophysical loadings signal are contained in the GPS time series. The findings reveal that earth body tide signals are more significant if compared to ocean tide loading signals because the magnitude of the earth body tide is greater than that of the ocean tide loading and it affects the coordinate system particularly at up component. Results illustrated the potential of GPS to provide the local parameters of the geophysical loadings that are beneficial for earth tidal modelling and that can be used to improve the quality of space geodetic measurements.
\end{abstract}

\section{INTRODUCTION}

Malaysian country is exposed to various types of natural hazards such as land subsidence, landslides, earthquakes and natural deformation phenomena as it close to the one of the most active seismic plate boundaries between the IndoAustralian and Eurasian Plate. This exposure indicates the implication toward the coordinate system, geodetic positioning, and deformation study in this country.

Generally, the realization of the reference coordinate system used in the satellite geodesy demands a good understanding about the dynamic of the earth. As eloquently stated by Abidin (2001), there are three types of earth dynamic that affect the coordinate system in satellite geodesy, which are the earth orbit around the sun alongside with the other planets, the earth rotation about its axis and the relatively slow movement of the earth's crust. The rotation of the earth has been affected by the gravitational force between the moon and the sun, the geophysical movement of mass distribution within the solid earth, ocean tide loading, atmospheric loading, and plate tectonic motions as shown in Figure 1 (Dickey, 1995; Abidin, 2001).

Furthermore, the gravitational attraction between the moon and sun along with the ocean tide water movement referred as earth body tide and ocean tide loading, respectively, periodically load and unload the solid earth causing the changes of displacement, tilt and gravity. The space geodetic measurements consist of GPS, VLBI and Altimeter required the correction from the tidal effect of geophysical loadings to maximize their extensive use in geodesy and geophysical studies such as monitoring the variations of mean sea level and quantifying the vertical land motion (Agnew, 2009).

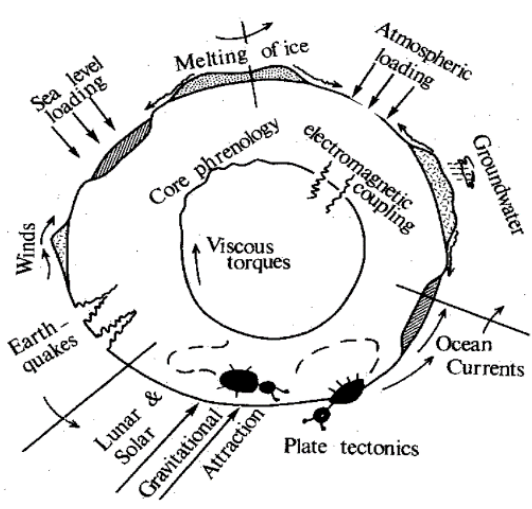

Figure 1. The forces that affect the earth rotation and the coordinate system (Dickey, 1995).

Conventionally, the precise point measurement of tidal response is commonly measured by various instruments such as superconducting gravimeters, strain meter and tilt observations. However, the rising cost of operation, the less data provided, the sparse distribution of station and the difficulty of accessing the best location for low-noise site causes inconsistent observations to expose the spatial heterogeneity of the solid earth tidal field (Ito et al., 2009). With the advent of precise space geodetic techniques such as GPS and VLBI, the study of the interior of the earth from the surface observations of the loading effects can provide the consistency of observations in revealing the spatial heterogeneity of the solid earth tidal field. In this study, the technology of GPS is utilised to investigate the presence of geophysical loadings as Malaysia has 78 GPS Continuously Operating Reference Station (CORS) stations distributed between 30 to $120 \mathrm{~km}$ apart since the VLBI stations are limited in number, with only 35 stations available worldwide (Ito et al., 2009; Jamil et al., 2010; Penna et al., 2015). 


\section{GPS OBSERVATION AND METHODOLOGY}

\subsection{GPS in Geophysical Loadings Study}

The GPS stations are susceptible to the periodic displacement due to the geophysical loadings. Several studies utilised GPS to determine the geophysical characteristics of the tidal variations, i.e. ocean tide loading, earth body tide and earth tide which is the summation of the earth body tide and ocean tide loading as well as the studies related to the validation of the geophysical loadings model with the GPS measurements (Vey et al., 2002; King et al., 2005; Ito et al., 2009; Bos et al., 2015; Penna et al., 2015; Alihan et al., 2019).

Most of these studies used a post-processed kinematic precise point positioning (KPPP) GPS analysis. This is in contrast to the GPS's relative positioning technique which can frequently minimize or eliminate the impacts of geophysical loadings on the earth's surface displacements if the stations are relatively close to each other (Milbert, 2017). Precise point positioning is an absolute positioning method that considered the error source where it has been reduced or neglected in the relative positioning such as phase wind up error, satellite phase center offset, earth body tide, ocean tide loading and pole tide (Raziq and Collier, 2006). The independent data from the external sources such the International GPS/GNSS Service (IGS) that supplied the precise orbit, clock and polar motion parameter should be utilised in order to deal with the noise that impact the required signal of absolute positioning observations. These approaches implement un-differenced dual-frequency pseudorange and carrier phase observations with the centimeter level of precision (Héroux and Kouba, 2001; Raziq and Collier, 2006).

\subsection{GPS Observations and Processing Methods}

In this study, a network of GPS CORS from MyRTKnet in the year 2013 is utilised. MyRTKnet consists of 50 GPS CORS over Peninsular Malaysia and 28 stations in Sabah and Sarawak which is operated by Department of Survey and Mapping Malaysia (DSMM). However, only 70 stations can be used in this study as the other eight (8) stations had bad observations during 2013.

An open source software RTKLIB with Comment User Interface (CUI) is employed for GPS data processing. This software is compatible for scientific studies in surveying fields that require standard and precise positioning. Kinematic Precise Point Positioning (KPPP) method is used in this study in order to estimate the geophysical loadings signal in GPS observations. Otherwise, the signal would be removed or reduced if the method used is differential GPS positioning. Figure 2 shows the main workflow of GPS data processing using RTKLIB.

The GPS data processing strategies include the data preparation of the 30 second data sampling to produce the daily solution, and the 10-degree elevation of mask angle is used for an increased number of observations and reduce the multipath error due to the obstructed area. The processing of the zero-difference measurements added the parameter of the precise ephemeris (.SP3), IGS Earth Rotation Parameter (.ERP), IGS final clock with sampling rate 30s (.CLK) and Differential Code Bias (.DCB) to reduce the noise that impact on the required signal in the GPS observations. Subsequently, the measurement model is applied in the KPPP GPS processing such as the satellite and receiver antenna phase variation center (.ATX), phase windup correction, Ionosphere-free linear combination with dual frequency and estimated zenith total delays and horizontal gradient parameters for troposphere correction. The static integer ambiguities are continuously estimated and resolved using fix and hold strategy. Table 1 summarizes the KPPP GPS processing strategies.

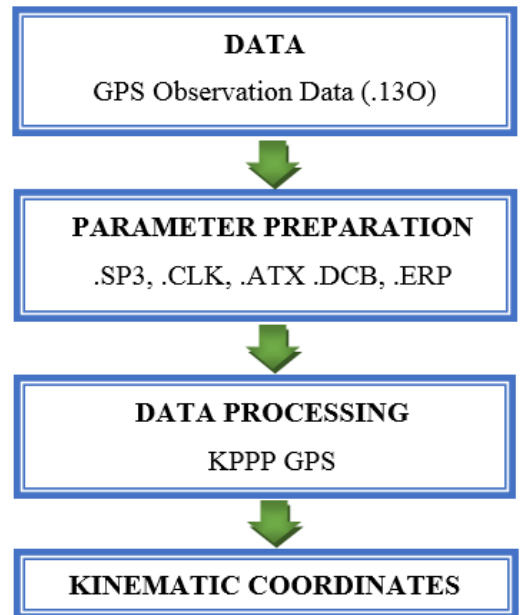

Figure 2. Main work flow of GPS data processing using RTKLIB.

\begin{tabular}{ll}
\hline \multicolumn{1}{c}{ Processing Parameters } & \multicolumn{1}{c}{ Processing Strategy } \\
\hline Availability Data & $1^{\text {st }}$ January 2013-31 $1^{\text {st }}$ December 2013 \\
Input data & Daily \\
Elevation cut-off angle & $10^{\circ}$ \\
Sampling rate & 30 second \\
Ionosphere correction & Ionosphere-Free (IF) linear combination \\
Troposphere correction & Estimated ZTD + Grad \\
Satellite Ephemeris/Clock & Precise \\
Integer Ambiguity Resolution & Fix and Hold \\
\hline
\end{tabular}

Table 1. The processing strategies.

\subsection{Estimation of Earth Body Tide, Ocean Tide Loading and Earth Tide based on KPPP GPS Observations}

Three configurations have been used in the processing to determine the signal of earth body tide, ocean tide loading and earth tide based on the GPS observations. These configurations will be clarified as follows:

Configuration 1: the processing strategies without applying any earth tide corrections.

Configuration 2: the processing strategies applying earth body tide correction using IERS2003 model.

Configuration 3: the processing strategies applying both earth body tide and ocean tide loading corrections using IERS2003 and FES2012 model.

From Configuration 1, the output processing contained all types of signals including earth body tide, ocean tide loading, atmospheric pressure loading, pole tide, non-geophysical phenomena and noise while the output of the processing from Configuration 2 consists of the signals of ocean tide loading, atmospheric pressure loading, pole tide, non-geophysical phenomena and noise. Configuration 3 contains only the signal of the atmospheric pressure loading, pole tide, non-geophysical 
phenomena and noise. Several parameters have been added in the processing strategies as mentioned in Section 2.2 to reduce the unwanted signal in the GPS observations.

In a discussion of geophysical loadings estimation on February 8,2017 , Wijaya stated that the earth body tide observed by the KPPP GPS is estimated by the difference of KPPP GPS solutions between Configuration 1 and Configuration 2 where these observations are obtained from the output of the earth body tide model and model error as shown in equation (1). Meanwhile the ocean tide loading derived from the KPPP GPS is determined by the difference of KPPP GPS solutions between Configuration 2 and Configuration 3 where these observations are acquired from the output of the ocean tide loading model and model error as presented in equation (2). Then, the earth tide also known as the total signal from the summation of the earth body tide and ocean tide loading based on the KPPP GPS observations shown in equation (3) (Wijaya, 2017).

$$
\begin{aligned}
& \widehat{E B T}=\widehat{E B T}+\varepsilon_{\overline{E B T}} \\
& \widehat{O T L}=\widehat{O T L}+\varepsilon_{\overline{O T L}} \\
& \widehat{E T}=\widehat{E B T}+\widehat{O T L}
\end{aligned}
$$

where $\widehat{\overparen{E B T}}=$ earth body tide derived from KPPP GPS

$\widehat{O T L}=$ ocean tide loading derived from KPPP GPS

$\widehat{E T}=$ earth tide derived from KPPP GPS

$\overline{E B T}=$ earth body tide model, IERS2003

$\overline{O T L}=$ ocean tide loading model, FES2012

$\varepsilon_{\overline{E B T}}=$ earth body tide model error

$\varepsilon \overline{\text { OTL }}=$ ocean tide loading model error

2.4 Evaluate the Percentage of Geophysical Loadings in GPS Observations using General Least Squares Approaches

The GPS observations consist of periodic and non-periodic signals. In this study, the periodic signals from the geophysical loadings that consist of earth body tide, ocean tide loading and earth tide is estimated based on the KPPP GPS solutions. However, the extent of the presence of this kind of the periodic signals in GPS observations is still unknown. Since all the configurations of GPS processing method that is Configuration 1, Configuration 2 and Configuration 3 accommodate both signals and errors as mentioned in the Section 2.3 , the general least squares method is used to estimate the presence of the earth body tide, ocean tide loading and earth tides contained within the GPS observations.

According to Ghilani and Wolf (2006), the method of general least squares implementing the adjustment that contains more than one measurement in the observation equations. This approach proposed that both of observation data at $\mathrm{x}$-axis and $\mathrm{y}$ axis contain residuals when fitting the observation point on a linear line (Ghilani and Wolf, 2006). Consider that the output from Configuration 1 which consisted all types of signals, including earth body tide, ocean tide loading, atmospheric pressure loading, pole tide, non-geophysical phenomena and errors as $\chi$ and the output from Configuration 2 that contained the signals of ocean tide loading, atmospheric pressure loading, pole tide, non-geophysical phenomena and errors as $\gamma$, then the mathematical model is written as (Ghilani and Wolf, 2006):

$$
F(\chi, \gamma)=\left(\gamma+v_{y}\right)-m\left(\chi+v_{\chi}\right)-c=0
$$

$$
\begin{aligned}
& v_{y}=\text { residuals of data } \gamma \\
& m=\text { the gradient of the straight line } \\
& c=\mathrm{y} \text {-axis intercept }
\end{aligned}
$$

Equation (4) is a non-linear and the unknown parameter that need to be estimated are $v_{x}, v_{y}, m$ and $c$. The non-linear equation (4) are linearized by using Taylor series approximation as follows (Ghilani and Wolf, 2006):

$$
F(\chi, \gamma) \approx F\left(\chi_{0}, \gamma_{0}\right)+\frac{\partial F}{\partial X} v_{X}+\frac{\partial F}{\partial y} v_{Y}+\frac{\partial F}{\partial m} d m+\frac{\partial F}{\partial c} d c
$$

The outcome of the linearized form is:

$$
\frac{\partial F}{\partial X} v_{X}+\frac{\partial F}{\partial y} v_{Y}+\frac{\partial F}{\partial m} d m+\frac{\partial F}{\partial e} d c=-\left(m_{0} X+c_{0}-\gamma\right)
$$

The partial derivatives of equation (6) are:

$$
\frac{\partial F}{\partial X}=-m, \frac{\partial F}{\partial y}=1, \frac{\partial F}{\partial m}=-\chi, \frac{\partial F}{\partial c}=-1
$$

Assume that there are four data points of measurements $A, B, C$ and $D$, substitute equation (7) into equation (6). The following mathematical models for the four data points of measurements can be written as:

$$
\begin{aligned}
& -m_{0} v_{X A}+v_{Y A}-\chi_{A} d m-d c=-\left(m_{0} \chi_{A}+c_{0}-\gamma_{A}\right) \\
& -m_{0} v_{X B}+v_{Y B}-\chi_{B} d m-d c=-\left(m_{0} \chi_{B}+c_{0}-\gamma_{B}\right) \\
& -m_{0} v_{X C}+v_{Y C}-\chi_{C} d m-d c=-\left(m_{0} \chi_{C}+c_{0}-\gamma_{C}\right) \\
& -m_{0} v_{X D}+v_{Y D}-\chi_{D} d m-d c=-\left(m_{0} \chi_{D}+c_{0}-\gamma_{D}\right)
\end{aligned}
$$

Equation (8) can be written in a matrix form as follows (Ghilani and Wolf, 2006):

$$
H V+J X=K
$$

$$
\begin{aligned}
& \text { where } \\
& H=\left[\begin{array}{cccccccc}
-m_{0} & 1 & 0 & 0 & 0 & 0 & 0 & 0 \\
0 & 0 & -m_{0} & 1 & 0 & 0 & 0 & 0 \\
0 & 0 & 0 & 0 & -m_{0} & 1 & 0 & 0 \\
0 & 0 & 0 & 0 & 0 & 0 & -m_{0} & 1
\end{array}\right] \\
& J=\left[\begin{array}{cc}
v_{X A} \\
\chi_{A} & -1 \\
-\chi_{B} & -1 \\
-\chi_{C} & -1 \\
-\chi_{D} & -1
\end{array}\right], \quad V=\left[\begin{array}{l}
v_{X B} \\
v_{Y B} \\
v_{X C} \\
v_{Y C} \\
v_{X D} \\
v_{Y D}
\end{array}\right], \quad X=\left[\begin{array}{l}
d m \\
d C
\end{array}\right] \\
& K=\left[\begin{array}{l}
-\left(m_{0} \chi_{A}+c_{0}-\gamma_{A}\right) \\
-\left(m_{0} \chi_{B}+c_{0}-\gamma_{B}\right) \\
-\left(m_{0} \chi_{C}+c_{0}-\gamma_{C}\right) \\
-\left(m_{0} \chi_{D}+c_{0}-\gamma_{D}\right)
\end{array}\right]
\end{aligned}
$$

Then the equivalent matrix system is (Ghilani and Wolf, 2006):

$$
I^{T} J X=J^{T} K
$$

where the unknown parameters in matrix $X$ can be estimated as follows:

$$
X=\left(J^{T} D\right)^{-1} J^{T} K
$$

where $\quad v_{X}=$ residuals of data $\chi$ 
As explained by Ghilani and Wolf, the unknown parameters in matrix $X$ are corrected by using the initial approximations as equation is a non-linear system and this method is iterated until the value in matrix $X$ converges. Later, the equivalent residual vector, $V_{e}$ is estimated as follows (Ghilani and Wolf, 2006):

$$
V_{e}=J X-K
$$

By using equation (12), the observational residual is computed as follows:

$$
V=H^{T} V_{e}
$$

The observations are updated corresponding to their residuals. Hence, the second iteration of the updated observations is (Ghilani and Wolf, 2006):

$$
l_{i}^{\prime}=l_{i}+v_{i}
$$

where

$$
\begin{aligned}
& l_{i}^{\prime}=\text { the second iterations of observations } \\
& l_{i}=\text { the original observations } \\
& v_{i}=\text { the residuals of the observations }
\end{aligned}
$$

As mentioned in Section 2.3, the earth body tide derived from the KPPP GPS is estimated by the difference of KPPP GPS solutions between Configuration 1 and Configuration 2. Figure 3 indicated the fitting points of a straight line from both observations from Configuration 1 and Configuration 2 after the process from equation (4) to equation (14).

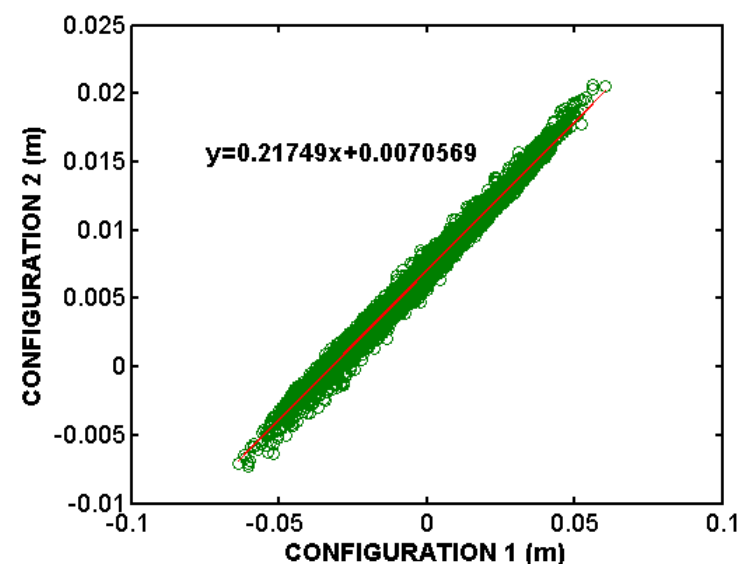

Figure 3. The fitting points between two configurations.

Since the output from Configuration 1 contained all types of signals while Configuration 2 consisted of all signals except earth body tide, the percentage of the other signals excluding the earth body tide, $P_{\text {other }}$, can be determined by applying the value of the gradient of a straight line, $m$ as follows:

$$
\begin{gathered}
m_{21}=\frac{\Delta \text { Configuration 2 }}{\Delta \text { Configuration 1 }} \\
P_{\text {other }}=m_{21} \times 100
\end{gathered}
$$

Then, the presence of the earth body tide, $P_{E B T}$ can be estimated as follows:

$$
P_{E B T}=\left(1-m_{21}\right) \times 100
$$

Next, the presence of ocean tide loading is determined by applying the gradient of a straight line from the observations of Configuration 2 and Configuration $3, m_{23}$ while the presence of earth tide is computed based on the total percentage of presence of both earth body tide and ocean tide loading as follows:

$$
\begin{aligned}
& P_{\text {OTL }}=\left(1-m_{23}\right) \times 100 \\
& P_{E T}=P_{E B T}+P_{O T L}
\end{aligned}
$$

\section{THE PRESENCE OF EARTH BODY TIDE, OCEAN TIDE LOADING AND EARTH TIDE SIGNALS IN GPS OBSERVATIONS}

The identification of the presence of the earth body tide, ocean tide loading and earth tide at 70 MyRTKnet stations is tabulated in Table 2 while the average of percentage of signals contained in KPPP GPS observations is charted in Figure 4 to 6 . The earth body tide, ocean tide loading and earth tide have a great contribution in the KPPP GPS observations as the assessment of the presence of each signal at the MyRTKnet stations indicated that the percentage of earth body tide signals are $65 \%$ to $86 \%$ at north component, $61 \%$ to $81 \%$ at east component and $85 \%$ to $94 \%$ at up component while the percentage of ocean tide loading signals in KPPP GPS observations are $1 \%$ to $7 \%$ at north component, $1 \%$ to $5 \%$ at east component and $1 \%$ to $7 \%$ at up component. The percentage of other signals contained in KPPP GPS are approximately to $10 \%$ to $33 \%, 17 \%$ to $36 \%$ and $4 \%$ to $12 \%$ at north, east and up component, respectively.

\section{The Percentage of Presence Signals in GPS Observations} (North Component)

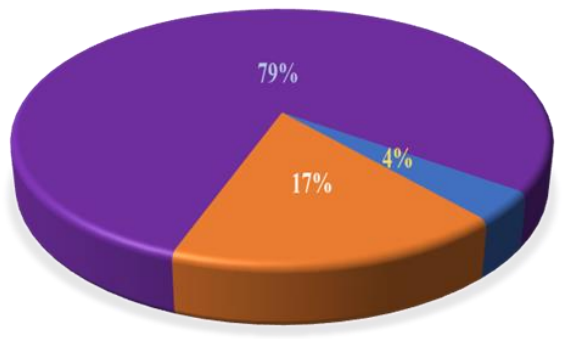

aEB $\mathbf{m O T L}$ a Others

Figure 4. The average of presence signals in GPS observations at north component.

The Percentage of Presence Signals in GPS Observations (East Component)

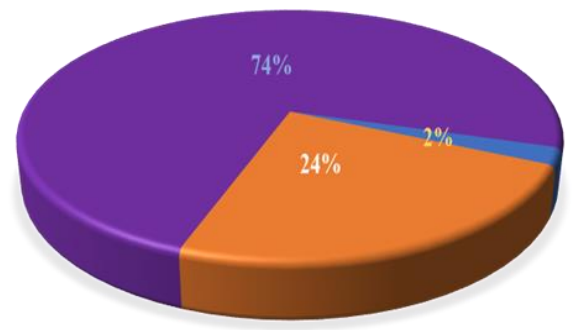

a EBT $\mathbf{m}$ OTL $\mathbf{m}$ Others

Figure 5. The average of presence signals in GPS observations at east component. 
The Percentage of Presence Signals in GPS Observations (Up Component)

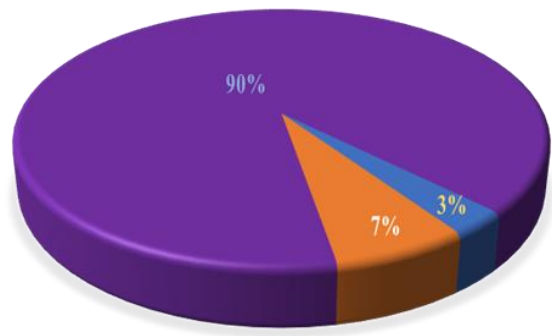

aEBT $\mathbf{a}$ OTL $\mathbf{a}$ Others

Figure 6. The average of presence signals in GPS observations at up component.

Based on Figure 4 to 6 , the geophysical loadings that consist of both earth body tide and ocean tide loadings have a great contribution in KPPP GPS observations with $79 \%$ of earth body tide signals, $4 \%$ of ocean tide loading signals and $17 \%$ of other signals at north component, $74 \%$ of earth body tide signals, $2 \%$ of ocean tide loading signals and $24 \%$ of other signals at east component and $90 \%$ of earth body tide signals, $3 \%$ of ocean tide loading signals and $7 \%$ of other signals at up component. The average percentage of total signals of earth tide are equivalent to $83 \%$ at north component, $76 \%$ at east component and $93 \%$ at up component where the signals of earth body tide are more significant compared to ocean tide loading signals.

The earth body tide is the largest periodic motion of the earth's crust compared to ocean tide loading which it can reach in the centimeter $(\mathrm{cm})$ level of displacements, about $5 \mathrm{~cm}$ in the horizontal plane and $20-30 \mathrm{~cm}$ in the up component. Meanwhile the magnitude of ocean tide loading is usually around the millimeter $(\mathrm{mm})$ level of displacement and more than $1 \mathrm{~cm}$ can be achieved when the geodetic stations are located very close to the shore (Pagiatakis, 1988; Héroux and Kouba, 2001; Zheng, 2007; Cai, 2009; Subirana et al., 2013; Alihan et al., 2019). Thus, the results obtained that earth body tide signals are more significant if compared to ocean tide loading signals because the magnitude of the earth body tide is greater than that of the ocean tide loading and it affects the coordinate system particularly at up component.

\begin{tabular}{|c|c|c|c|c|c|c|c|c|c|c|c|c|}
\hline \multirow{2}{*}{ Stations } & \multicolumn{4}{|c|}{ North Component (\%) } & \multicolumn{4}{|c|}{ East Component (\%) } & \multicolumn{4}{|c|}{ Up Components (\%) } \\
\hline & EBT & OTL & ET & OT & EBT & OTL & ET & OT & EBT & OTL & ET & OT \\
\hline AMAN & 76 & 4 & 80 & 20 & 76 & 3 & 79 & 21 & 89 & 4 & 93 & 7 \\
\hline ARAU & 68 & 2 & 70 & 30 & 63 & 1 & 64 & 36 & 89 & 1 & 90 & 10 \\
\hline AYER & 79 & 3 & 81 & 19 & 71 & 1 & 72 & 28 & 91 & 2 & 93 & 7 \\
\hline BABH & 82 & 4 & 86 & 14 & 70 & 2 & 72 & 28 & 92 & 1 & 93 & 7 \\
\hline BAHA & 74 & 4 & 78 & 22 & 67 & 4 & 71 & 29 & 89 & 3 & 92 & 8 \\
\hline BANT & 82 & 5 & 87 & 13 & 74 & 5 & 79 & 21 & 89 & 4 & 93 & 7 \\
\hline BEAU & 77 & 2 & 79 & 21 & 74 & 1 & 75 & 25 & 88 & 5 & 93 & 7 \\
\hline BEHR & 80 & 4 & 84 & 16 & 73 & 3 & 76 & 24 & 90 & 3 & 93 & 7 \\
\hline BELU & 78 & 2 & 80 & 20 & 74 & 1 & 75 & 25 & 91 & 3 & 94 & 6 \\
\hline BIN1 & 80 & 3 & 83 & 17 & 79 & 1 & 80 & 20 & 89 & 3 & 92 & 8 \\
\hline CAME & 71 & 3 & 74 & 26 & 70 & 2 & 72 & 28 & 90 & 2 & 92 & 8 \\
\hline CENE & 85 & 4 & 89 & 11 & 78 & 3 & 81 & 19 & 91 & 4 & 95 & 5 \\
\hline GAJA & 80 & 6 & 86 & 14 & 74 & 3 & 77 & 23 & 91 & 3 & 94 & 6 \\
\hline GETI & 86 & 2 & 89 & 11 & 78 & 1 & 79 & 21 & 92 & 3 & 95 & 5 \\
\hline GMUS & 65 & 2 & 67 & 33 & 62 & 2 & 64 & 36 & 87 & 2 & 89 & 11 \\
\hline GRIK & 79 & 3 & 82 & 18 & 72 & 1 & 73 & 27 & 93 & 1 & 94 & 6 \\
\hline JRNT & 78 & 4 & 82 & 18 & 76 & 3 & 79 & 21 & 91 & 3 & 94 & 6 \\
\hline JUML & 82 & 5 & 87 & 13 & 74 & 5 & 79 & 21 & 89 & 5 & 94 & 6 \\
\hline KAPI & 78 & 2 & 80 & 20 & 78 & 2 & 80 & 20 & 91 & 3 & 94 & 6 \\
\hline KENI & 82 & 2 & 84 & 16 & 79 & 1 & 80 & 20 & 89 & 3 & 92 & 8 \\
\hline KLAW & 82 & 4 & 86 & 14 & 74 & 4 & 78 & 22 & 90 & 4 & 94 & 6 \\
\hline KRAI & 78 & 3 & 81 & 19 & 69 & 1 & 70 & 30 & 90 & 2 & 92 & 8 \\
\hline KROM & 81 & 7 & 88 & 12 & 74 & 4 & 78 & 22 & 91 & 4 & 95 & 5 \\
\hline KUAL & 81 & 3 & 84 & 16 & 70 & 2 & 72 & 28 & 90 & 3 & 93 & 7 \\
\hline KUDA & 82 & 1 & 83 & 17 & 76 & 1 & 77 & 23 & 90 & 4 & 94 & 6 \\
\hline KUKP & 81 & 6 & 87 & 13 & 73 & 2 & 75 & 25 & 91 & 2 & 93 & 7 \\
\hline LAB1 & 76 & 2 & 78 & 22 & 76 & 1 & 77 & 23 & 88 & 3 & 91 & 9 \\
\hline LASA & 82 & 3 & 85 & 15 & 77 & 1 & 78 & 22 & 93 & 1 & 94 & 6 \\
\hline LAWS & 77 & 2 & 79 & 21 & 73 & 1 & 74 & 26 & 89 & 4 & 93 & 7 \\
\hline LGKW & 82 & 2 & 84 & 16 & 73 & 2 & 75 & 25 & 94 & 1 & 95 & 5 \\
\hline MERS & 82 & 7 & 89 & 11 & 77 & 3 & 80 & 20 & 91 & 4 & 95 & 5 \\
\hline MERU & 75 & 5 & 80 & 20 & 66 & 4 & 70 & 30 & 89 & 5 & 94 & 6 \\
\hline MIRI & 82 & 3 & 85 & 15 & 74 & 1 & 75 & 25 & 89 & 3 & 92 & 8 \\
\hline MRDI & 73 & 2 & 75 & 25 & 68 & 1 & 69 & 31 & 86 & 3 & 89 & 11 \\
\hline MRDU & 76 & 2 & 78 & 22 & 73 & 1 & 74 & 26 & 89 & 4 & 93 & 7 \\
\hline
\end{tabular}




\begin{tabular}{|c|c|c|c|c|c|c|c|c|c|c|c|c|}
\hline MTAW & 78 & 1 & 79 & 21 & 78 & 3 & 81 & 19 & 86 & 6 & 92 & 8 \\
\hline MUAD & 84 & 5 & 89 & 11 & 77 & 4 & 81 & 19 & 91 & 3 & 94 & 6 \\
\hline MUKA & 77 & 5 & 82 & 18 & 75 & 3 & 78 & 22 & 91 & 3 & 94 & 6 \\
\hline MUKH & 85 & 4 & 89 & 11 & 79 & 2 & 81 & 19 & 92 & 3 & 95 & 5 \\
\hline NIAH & 77 & 3 & 80 & 20 & 71 & 1 & 72 & 28 & 89 & 3 & 92 & 8 \\
\hline PDIC & 81 & 4 & 85 & 15 & 73 & 5 & 78 & 22 & 89 & 5 & 94 & 6 \\
\hline PEKN & 84 & 5 & 89 & 11 & 75 & 4 & 79 & 21 & 91 & 4 & 95 & 5 \\
\hline PRTS & 78 & 6 & 84 & 16 & 61 & 3 & 64 & 36 & 88 & 3 & 91 & 9 \\
\hline PUPK & 83 & 6 & 89 & 11 & 76 & 2 & 78 & 22 & 91 & 1 & 92 & 8 \\
\hline PUSI & 81 & 4 & 85 & 15 & 75 & 2 & 77 & 23 & 92 & 1 & 93 & 7 \\
\hline RANA & 78 & 2 & 80 & 20 & 77 & 1 & 78 & 22 & 89 & 4 & 93 & 7 \\
\hline SAND & 76 & 2 & 78 & 22 & 71 & 1 & 72 & 28 & 88 & 5 & 93 & 7 \\
\hline SARA & 79 & 5 & 84 & 16 & 78 & 3 & 81 & 19 & 90 & 3 & 93 & 7 \\
\hline SBKB & 83 & 6 & 89 & 11 & 76 & 4 & 80 & 20 & 90 & 3 & 93 & 7 \\
\hline SEG1 & 79 & 5 & 84 & 16 & 71 & 4 & 75 & 25 & 90 & 4 & 94 & 6 \\
\hline SEMA & 74 & 7 & 81 & 19 & 75 & 1 & 76 & 24 & 88 & 3 & 91 & 9 \\
\hline SEMP & 81 & 2 & 83 & 17 & 81 & 2 & 83 & 17 & 85 & 7 & 92 & 8 \\
\hline SETI & 69 & 2 & 71 & 29 & 64 & 1 & 65 & 35 & 85 & 3 & 88 & 12 \\
\hline SGPT & 81 & 3 & 84 & 16 & 77 & 1 & 78 & 22 & 93 & 1 & 94 & 6 \\
\hline SIB1 & 78 & 3 & 81 & 19 & 77 & 3 & 80 & 20 & 90 & 3 & 93 & 7 \\
\hline SIK1 & 73 & 2 & 75 & 25 & 68 & 1 & 69 & 31 & 92 & 1 & 93 & 7 \\
\hline SPGR & 82 & 7 & 89 & 11 & 79 & 3 & 82 & 18 & 92 & 4 & 96 & 4 \\
\hline SRIJ & 82 & 4 & 86 & 14 & 76 & 4 & 80 & 20 & 91 & 3 & 94 & 6 \\
\hline TEBE & 77 & 5 & 82 & 18 & 74 & 1 & 75 & 25 & 90 & 3 & 93 & 7 \\
\hline TENM & 82 & 2 & 84 & 16 & 78 & 2 & 80 & 20 & 89 & 4 & 93 & 7 \\
\hline TERI & 82 & 3 & 85 & 15 & 79 & 2 & 81 & 19 & 90 & 4 & 94 & 6 \\
\hline TGPG & 77 & 7 & 84 & 16 & 74 & 2 & 76 & 24 & 91 & 3 & 94 & 6 \\
\hline TLKI & 76 & 4 & 80 & 20 & 73 & 2 & 75 & 25 & 91 & 2 & 93 & 7 \\
\hline TLOH & 86 & 4 & 90 & 10 & 76 & 4 & 80 & 20 & 91 & 4 & 95 & 5 \\
\hline TMBN & 80 & 2 & 82 & 18 & 76 & 2 & 78 & 22 & 90 & 3 & 93 & 7 \\
\hline TOKA & 79 & 2 & 81 & 19 & 76 & 1 & 77 & 23 & 92 & 1 & 93 & 7 \\
\hline UMAS & 76 & 6 & 82 & 18 & 72 & 2 & 74 & 26 & 89 & 3 & 92 & 8 \\
\hline UPMS & 83 & 5 & 88 & 12 & 74 & 4 & 78 & 22 & 90 & 3 & 93 & 7 \\
\hline USMP & 80 & 3 & 83 & 17 & 74 & 1 & 75 & 25 & 92 & 1 & 93 & 7 \\
\hline UUMK & 78 & 2 & 80 & 20 & 70 & 1 & 71 & 29 & 94 & 1 & 95 & 5 \\
\hline
\end{tabular}

Table 2. The percentage of presence of earth body tide (EBT), ocean tide loading (OTL), earth tide (ET) and other signals (OT) in GPS observations.

\section{CONCLUDING REMARKS}

The earth is an elastic body which undergoes periodic displacements due to the geophysical loadings consisting of earth body tide, ocean tide loading and earth tide. A total of 70 MyRTKnet stations that covered both Peninsular and East Malaysia during the year 2013 and the processing method of KPPP GPS is utilised to estimate the geophysical loadings of the earth body tide, ocean tide loading and earth tide and to assess the percentage of the geophysical loadings contained in the GPS observations using general least squares approaches. The findings reveal that the presence of the geophysical loadings are large significant in the GPS observations particularly at up component.

\section{ACKNOWLEDGEMENTS}

Geomatic Innovation Research Group (GnG), Faculty of Built Environment and Surveying, Universiti Teknologi Malaysia and Geodesy Research Group, Faculty of Earth Sciences and Technology, Institute of Technology Bandung, Bandung, Indonesia are greatly acknowledged. Furthermore, the authors would like to express their gratitude to Department of Surveying and Mapping Malaysia (DSMM) for providing valuable MyRTKnet data for the uses of this study. We are grateful to the Ministry of Education (MOE) Malaysia and Universiti Teknologi Malaysia for funding this research under Research University Grant (VOT number: Q.J130000.2527.19H26).

\section{REFERENCES}

Abidin, H. Z. (2001). Geodesi Satelit. Edition 1. Jakarta: PT Pradnya Paramita.

Agnew, D. C. (2009). Earth Tides. G. Schubert (Ed.) Geodesy: Treatise on Geophysics. (163-195). Radarweg 29, 1043 NX Amsterdam, the Nertherlands: Elsevier B. V.

Alihan, N. S. A., Wijaya, D. D., Din, A. H. M., Bramanto, B., and Omar, A. H. (2019). Spatiotemporal Variations of Earth Tidal Displacement over Peninsular Malaysia based on GPS Observations. B. Pradhan (Ed.) GCEC 2017 Lecture Notes in Civil Engineering. (809-823). Singapore: Springer.

Bos, M. S., Penna, N. T., Baker, T. F., and Clarke, P. J. (2015). Ocean tide loading displacements in western Europe: 2 GPS-observed anelastic dispersion in the asthenosphere. Journal of Geophysical Research: Solid Earth. 120 (9), 65406557. 
Cai, C. (2009). Precise point positioning using dual-frequency GPS and GLONASS measurements. Degree of Master Science. Department of Geomatics Engineering, University of Calgary, Alberta.

Dickey, J. O. (1995). Earth Rotation. T. J. Ahrens (Ed.) Global earth physics: a handbook of physical constants. (356-368). Washington, D.C: American Geophysical Union.

Ghilani, C. D., and Wolf, P. R. (2006). Adjustment Computations Spatial Data Analysis. 4th Edition. Inc., Hoboken, New Jersey: John Willey \& Sons.

Héroux, P., and Kouba, J. (2001). GPS precise point positioning using IGS orbit products. Physics and Chemistry of the Earth, Part A: Solid Earth and Geodesy. 26 (6), 573-578.

Ito, T., Okubo, M., and Sagiya, T. (2009). High resolution mapping of Earth tide response based on GPS data in Japan. Journal of Geodynamics. 48 (3-5), 253-259.

Jamil, H., Mohamed, A., and Chang, D. (2010). The Malaysia real-time kinematic GNSS network (MyRTKnet) in 2010 and beyond. FIG Congress 2010. 11-16 April 2010. Sydney, Australia, 1-15.

King, M. A., Penna, N. T., Clarke, P. J., and King, E. C. (2005). Validation of ocean tide models around Antarctica using onshore GPS and gravity data. Journal of Geophysical Research: Solid Earth. 110 (B08401).

Milbert, D. (2017). Solid Earth Tide. Retrieved from http://geodesyworld.github.io/SOFTS/solid.htm

Pagiatakis, S. D. (1988). Ocean tide loading on a selfgravitating, compressible, layered, anistropic, viscoelastic and rotating earth with solid inner core and fluid outer core. Degree of Doctor of Philosophy. Department of Surveying Engineering, University of New Brunswick, Fredericton, N. B. Canada.

Penna, N. T., Clarke, P. J., Bos, M. S., and Baker, T. F. (2015). Ocean tide loading displacements in western Europe: 1. Validation of kinematic GPS estimates. Journal of Geophysical Research: Solid Earth. 120 (9), 6523-6539.

Raziq, N., and Collier, P. (2006). High precision GPS deformation monitoring using single receiver carrier phase data. F. Sansò \& A. J. Gil (Ed.) Geodetic Deformation Monitoring: From Geophysical to Engineering Roles. (95-102). Berlin Heidelberg New York: Springer.

Subirana, J. S., Zornoza, J. M. J., and Hernández-Pajares, M. (2013). GNSS data processing, Vol. I: Fundamentals and algorithms. Netherlands: ESA Communications.

Vey, S., Calais, E., Llubes, M., Florsch, N., Woppelmann, G., Hinderer, J., Amalvict, M., Lalancette, M. F., Simon, B., Duquenne, F., and Haase, J. S. (2002). GPS measurements of ocean loading and its impact on zenith tropospheric delay estimates: a case study in Brittany, France. Journal of Geodesy. $76(8), 419-427$.

Wijaya, D. D. (2017). Discussion on estimation of the geophysical loadings. Unpublished note, Kelompok Keilmuan Geodesi, Institut Teknologi Bandung, Indonesia.
Zheng, Y. (2007). Generation of network-based differential corrections for regional GNSS services. Degree of Doctor of Philosophy. Faculty of the Built Environment and Engineering, Queensland University of Technology, Australia.

Revised August 2019 